$\begin{array}{ll} & \text { Etnográfica } \\ \text { etnográfica } & \text { Revista do Centro em Rede de Investigação em }\end{array}$

Antropologia

vol. 17 (1) | 2013

Vol. $17(1)$

\title{
Malária, mosquitos e ruralidade no Portugal do século XX
}

Malaria, mosquitoes and the rural world in twentieth century Portugal

\section{Mónica Saavedra}

\section{(2) OpenEdition}

\section{Journals}

\section{Edição electrónica}

URL: https://journals.openedition.org/etnografica/2545

DOI: 10.4000/etnografica.2545

ISSN: 2182-2891

\section{Editora}

Centro em Rede de Investigação em Antropologia

\section{Edição impressa}

Data de publição: 1 fevereiro 2013

Paginação: 51-76

ISSN: 0873-6561

\section{Refêrencia eletrónica}

Mónica Saavedra, «Malária, mosquitos e ruralidade no Portugal do século XX», Etnográfica [Online], vol. 17 (1) | 2013, posto online no dia 13 março 2013, consultado o 09 fevereiro 2022. URL: http:// journals.openedition.org/etnografica/2545 ; DOI: https://doi.org/10.4000/etnografica.2545

\section{(c) (i) (8)}

Etnográfica is licensed under a Creative Commons Attribution-NonCommercial 4.0 International License. 


\section{Malária, mosquitos e ruralidade no Portugal do século XX}

\section{Mónica Saavedra}

Este artigo centra-se nas memórias de antigos trabalhadores rurais sobre "ter malária”. Parte-se das descrições da experiência física da doença e sua relação com as práticas quotidianas, particularmente as relacionadas com o trabalho, para uma análise sobre multiplicidade e complexidade das definições da malária. Pretende-se realçar a dimensão sociopolítica desta doença, subjacente às memórias recolhidas, bem como o caráter circunstancial, adaptável e pragmático das práticas envolvidas.

PALAVRAS-CHAVE: malária, práticas, mundo rural, trabalho, Portugal, século XX.

Malaria, mosquitoes and the rural world in twentieth century Portugal This article centres on former rural workers' memories of "having malaria". Focusing on descriptions of the disease's physical experience and its relation with everyday working practices, the multiplicity and complexity of malaria's definition will be analyzed. Malaria's socio-political dimension, underlying the collected memories, as well as the circumstantialities, adaptability and pragmatism of the practices related to the disease will be highlighted.

KEYWORDS: malaria, practices, rural world, work, Portugal, twentieth century.

SAAVEDRA, Mónica (maamsaa@gmail.com) - Centro em Rede de Investigação em Antropologia, ISCTE - Instituto Universitário de Lisboa, Portugal; Centre for Global Health Histories, University of York, Reino Unido. 
NESTE ARTIGO PROPONHO UMA REFLEXÃO SOBRE A COMPLEXIDADE DAS definições de malária, expressa nas diferentes práticas (técnicas e discursivas), direta ou indiretamente ligadas com esta doença. ${ }^{1}$ Centro-me nas narrativas de antigos trabalhadores rurais, homens e mulheres, das regiões arrozeiras dos vales do Tejo e do Sado, convocando a sua rememoração presente de "ter malária”, para realçar a receção e os usos sociais das práticas médicas associadas a esta doença, em relação com as vicissitudes e imperativos das condições materiais de vida quotidiana.

Se a partir da viragem do século XIX para o século XX prevalece a explicação que estabelece um parasita (Plasmodium) como a causa da infeção e um mosquito (Anopheles) como vetor da transmissão do parasita ao homem, esta aparente simplificação não elide a complexidade dos aspetos ecológicos, sociais e políticos que envolviam (e continuam a envolver) a malária. Esta complexidade da definição da malária não é apenas percetível nas fontes documentais - médicas -, onde as populações afetadas pela doença surgem sobretudo como objeto de conceptualizações, classificações e técnicas. Também os discursos daqueles que, até cerca de 1960, experimentaram "as sezões"2 na pele congregam essa multiplicidade de fatores e práticas que davam realidade a esta doença.

A malária emerge dos discursos tendo por eixo central o corpo como instrumento de trabalho e é inextricável da materialidade do quotidiano, bem como das rotinas laborais. Ressalta a definição compósita desta doença, cruzando habitus corporal, técnicas e ritmos de trabalho agrícola, relações sociais e de trabalho, definições, modelos e técnicas médicas e institucionais. A malária é definida nesta interface de práticas. Tem um lugar intermitente e secundário na ordem das prioridades quotidianas da vida dos indivíduos.

A “teoria da prática", na sua transdisciplinaridade, fluidez e ecletismo - de que Theodore Schatzki (2001) e Andreas Reckwitz (2002) dão conta, fazendo como que uma súmula das diferentes, e por vezes destoantes, perspetivas sobre "a prática" -, oferece a flexibilidade para abarcar a multiplicidade e complexidade de ações e interações presentes nas memórias de “ter malária”. Pensar as práticas não é aqui uma opção teórico-metodológica de partida, para a recolha e análise dessas memórias; é uma perspetiva sugerida pelo próprio terreno de observação, na diversidade das fontes e dos discursos sobre a malária.

É na(s) prática(s) que qualquer doença se configura como tal, revelando-se heterogénea nas formas que assume e volátil na sua caracterização. A doença é um "fenómeno 'biocultural" (Löwy 2001: 19), ${ }^{3}$ um conjunto determinado de manifestações físicas causadoras de desconforto, dor e eventualmente morte,

1 Este artigo é parte de uma tese de doutoramento (Saavedra 2010).

2 O termo "sezões" era, até ao desaparecimento da malária em Portugal, na segunda metade do século XX, a designação popular para esta doença.

3 Todas as traduções de citações em língua estrangeira são da responsabilidade da autora. 
ao qual se associam práticas conceptuais (definições), discursivas (designações, nomeações) e técnicas que diferem ao longo do tempo e no espaço (Rosenberg 1992; Singer e Clair 2003; Pussetti 2006).

As práticas quotidianas, na sua multiplicidade, combinação e adequação mútuas, na sua "produção substantiva de ordem em ocasiões singulares" (Lynch 2001: 131, ênfase no original) revelaram-se produtoras de sentidos na descrição das experiências pessoais de "ter malária". Trata-se de compreender a relação e sintonia - tuning, segundo a designação de Pickering (2001) - entre um conjunto de práticas que, articuladas entre si, conferem significado à malária, constituindo-a como interferência disruptiva por referência às rotinas diárias, e que implicam um conjunto de ações individuais e coletivas para resolver essa interferência identificada como um problema concreto, circunstancial e transitório. Compreendem-se assim as práticas como necessárias e simultaneamente performativas e significativas (Schatzki 1996).

O corpo é um elemento importante na pluralidade de perspetivas teóricas sobre as práticas, já que qualquer prática implica a respetiva incorporação (Schatzki 1996, 2001; Mol 2002; Reckwitz 2002). É também o aglutinador de diversas práticas incorporadas, relacionadas nos discursos sobre "ter malária". Não sendo explicitamente mencionado, o corpo insinua-se na constante referência ao sofrimento, ao frio e ao calor; na descrição das condições e técnicas de trabalho; na referência, por vezes envergonhada, à higiene corporal; na descrição e dramatização dos sintomas da malária. O corpo reúne as práticas incorporadas do trabalho e das rotinas familiares, relacionando-as com a malária, sobre a qual só faz sentido discursar tendo essa ligação por referência.

Enquanto para a medicina a relação entre malária e arrozais era epidemiológica, sendo os campos de arroz a potencial "causa ambiental" desta doença (Landeiro e Cambournac s.d.), para os trabalhadores rurais o trabalho no arroz era, acima de tudo, um dos símbolos da sua condição social dependente e subalterna, de trabalho árduo e duro, de provações físicas, entre as quais se contava, sem protagonismos, a malária.

Estamos perante um "corpo múltiplo" (Mol 2002). Era definido pelas práticas da malariologia como baços dilatados e índices esplénicos, sangue infetado e testes de gota espessa ou esfregaços (Figueira e Landeiro 1932). Mas, para quem incorporava a malária, era descrito pelos arrepios, os vómitos, a febre, os apetites inusitados e pela incapacidade, ainda que temporária, de cumprir as rotinas do trabalho. A discussão sobre a produção do corpo pelas práticas (Schatzki 1996, 2001; Reckwitz 2002) vai muito além da análise que aqui se pretende trazer sobre as memórias de "ter malária". Importa antes compreender a especificidade da centralidade do corpo na performatividade dos discursos e ações que constituem a malária, para os antigos trabalhadores rurais.

No contexto português, seguindo as memórias daqueles que tiveram malária, não encontramos, como em Itália (Snowden 2006), participação organizada e 
politicamente engajada com a ação institucional para o controlo desta doença, nem resistência a essa ação, enquanto expressão de diversidade cultural, como no México (Cueto 2007). Encontramos, sim, apropriação e articulação de recursos múltiplos, de acordo com a interpretação e experiência imediata da malária; ou seja, convocação de práticas conformes com "circunstâncias particulares" (Lynch 2001: 131).

A malária, captada pela rememoração de experiências passadas, inclui como eixo a noção de "sofrimento" partilhado por um grupo de indivíduos, congregando os elementos e gestos do quotidiano com as hierarquias sociais e as relações de trabalho. As narrativas sobre as experiências pessoais da malária remetem para a necessidade de considerar os diversos fatores micro e macrossociais envolvidos nessas experiências, condicionando a vulnerabilidade e possibilidades de resposta dos indivíduos à doença, na linha do conceito de "sofrimento social" desenvolvido por Arthur Kleinman, Veena Das e Margaret Lock (1996, 1997), reconhecendo a relevância da historicidade das condições políticas, sociais e económicas que geram esse sofrimento, bem como o modo como é vivido e percebido (Farmer 2004). ${ }^{4}$

\section{ORDENANDO O SOFRIMENTO: "E ERA AÍ QUE CHEGAVAM AS SEZÕES"}

A escolha das regiões dos vales do Tejo e Sado (particularmente, Águas de Moura, Alcácer do Sal, Azambuja e Benavente) para procurar as memórias sobre "as sezões" seguiu as classificações médicas da malária como uma doença rural, fundamentalmente - embora não exclusivamente - ligada à cultura do arroz. ${ }^{5}$ Esta representação inscrevia-se numa geografia médica que identificava e classificava determinadas regiões, conforme a endemicidade da malária, reificando ainda a ligação centenária e amplamente popularizada dos arrozais com esta doença (Landeiro e Cambournac s. d.).

Em Águas de Moura, Alcácer do Sal, Azambuja e Benavente encontravam-se grandes propriedades que permitiam a prática de cultura extensiva,

4 Para outros enquadramentos da noção de sofrimento no âmbito das questões da saúde, veja-se, por exemplo, o dossiê dedicado ao "sofrimento social" organizado por Chiara Pussetti e Micol Brazzabeni (201 1), e também alguns trabalhos que integram a coletânea organizada por Luís Silva Pereira e Chiara Pussetti (2009).

5 Ficaram deliberadamente de fora do âmbito desta pesquisa a região dos campos de arroz do Mondego, onde existiram uma estação e um posto antissezonáticos (Montemor-o-Velho e Soure, respetivamente); bem como a região do Pocinho, no Alto Douro, e de Idanha-a-Nova (Castelo Branco), que também tinham um posto antissezonático e onde a malária não estava associada aos arrozais. Quando se estabeleceu a primeira estação antissezonática (em 1931), não se observavam casos significativos de malária no distrito de Aveiro e no delta do Vouga, apesar da existência de extensos campos de arroz. Este facto era explicado pelos malariologistas como resultado das condições climáticas daquela região e da criação de gado estabulado, que gerava as condições ideais para desviar os mosquitos dos homens para os animais (Cambournac 1947: 15). 
nomeadamente do arroz, empregando grande número de trabalhadores rurais. ${ }^{6}$ Assim, nestas localidades, ao escolher a via institucional (lares e centros de dia) para a recolha de depoimentos sobre as experiências pessoais de "ter malária”, os antigos membros deste grupo profissional estiveram fortemente representados. ${ }^{7}$

As primeiras entrevistas deixaram claro que a malária era um acontecimento menor na vida desses assalariados, contrastanto com a importância que lhe era dada pelas instâncias médicas, na altura. As "sezões" perdiam sobretudo relevância perante as experiências/memórias do trabalho no campo. Os entrevistados descreviam com grande ênfase e detalhe as condições, ritmo e tipo dos trabalhos rurais desempenhados, a pobreza e despojamento reinantes. Remetiam as suas memórias individuais para o universo das experiências partilhadas por um grupo profissional (trabalhadores rurais), transformando-as em memórias coletivas. Pretendiam, assim, conferir legitimidade e veracidade ao seu discurso, dando-lhe o valor de um depoimento sobre uma época e uma realidade social.

Era neste pano de fundo que surgia a malária como acidente, memória ora banalizada e vaga, entre as doenças da infância, ora percebida como impedimento ao exercício do trabalho, marco fundamental da identidade dos indivíduos. Estes, não sendo herdeiros de linhagens ou propriedades, tinham de facto como "único capital [...] o seu trabalho, pelo que defend[iam] e apoia[vam] um sistema no qual [era] a própria nobreza do trabalho que confer[ia] determinado status ao trabalhador" (Cutileiro 1977: 62).

A nostalgia do passado, confundindo-se com a ideia de sofrimento, perpassou a maioria das entrevistas, sendo frequente o rematar de fragmentos das narrativas com a afirmação "sofreu-se muito". Trata-se de um "sofrimento social” (Kleinman, Das y Lock 1996, 1997), que inclui não apenas o padecimento físico decorrente da doença, mas sobretudo aquele provocado pela

6 Segundo Rosas et al. (1994), no início da década de 50 do século passado as explorações com mais de 100 hectares representavam apenas $0,4 \%$ do número total de explorações agrícolas, mas aproximadamente $45 \%$ da terra arável, concentrando-se sobretudo nos distritos de Évora, Beja, Portalegre e Setúbal. Da população ativa ocupada na agricultura em 1950, havia, no distrito de Lisboa (ao qual pertence Azambuja, localizada na lezíria do Tejo), 9453 patrões, 10.728 isolados (pequenos proprietários) e 60.627 assalariados; no distrito de Santarém (ao qual pertence Benavente, concelho atravessado pelo Sorraia), 8500 patrões, 15.411 isolados e 80.252 assalariados; no distrito de Setúbal (ao qual pertencem Águas de Moura, no concelho de Palmela, e Alcácer do Sal), 3049 patrões, 3705 isolados e 40.609 assalariados. Em 1960, em Lisboa havia 4840 patrões, 10.921 isolados e 52.358 assalariados; em Santarém, 5844 patrões, 12.136 isolados e 71.254 assalariados; em Setúbal, 2355 patrões, 2576 isolados e 30.686 assalariados (INE 1960, 1965).

7 A escolha da via institucional para chegar aos potenciais entrevistados, bem como a escolha das regiões mencionadas para procurar as memórias da malária determinaram as vozes presentes neste trabalho, com as limitações, exclusões e ausências que lhes são inerentes. Outras profissões estavam também representadas entre os entrevistados (avieiros, calceteiros, empregadas domésticas, etc.), mas as suas memórias da malária não diferiam significativamente das dos trabalhadores rurais, que eram em número mais expressivo. 
ameaça da fome, excesso, falta ou violência do trabalho, desigualdade, exploração, etc. Nestas condições, para os entrevistados não fazia sentido falar sobre a malária - episódio esporádico ao longo das suas vidas, pontual e passageiro - sem falar dos outros sofrimentos, persistentes e inelutáveis.

Contudo, as entrevistas sugeriam perceções desse sofrimento divergentes no tempo; i. e., sugeriam que o sofrimento explícito ou implícito nas memórias relatadas não tinha no presente, para os entrevistados, o mesmo significado que teve no tempo a que se reportavam, o que ficou claro no seguinte comentário: "A gente não estranhava porque a gente quando abriu os olhos já foi neste ambiente". Os discursos dos entrevistados revelaram uma "reflexividade retrospetiva", uma avaliação das condições materiais de vida e trabalho passados à luz dos modelos presentemente dominantes sobre as relações e leis de trabalho, a opressão ditatorial do regime do Estado Novo, as condições de salubridade, a democratização da assistência na saúde, etc. Desta sobreposição de experiências e referências resultaram discursos que cruzam os registos apologético, lastimoso e fatalista; a consciência crítica da desigualdade, privações e repressão subjacentes à sua condição social - geradora de mágoa, por vezes de revolta, no presente -; a nostalgia do corpo ativo e jovem; o julgamento da superioridade dos valores então associados ao trabalho; e, por fim, a noção de uma vida social mais genuína, mas também de um "destino social" inevitável.

Neste contexto, as práticas que definem a malária para os trabalhadores rurais estão sujeitas a circunstâncias específicas relacionadas com a construção da memória, a posição social e a biografia dos indivíduos, compreendidas no âmbito de um processo histórico e enquadradas numa ordem política, económica e social situada no espaço e no tempo.

\section{IDEOLOGIA, ECONOMIA E SAÚDE NO ESTADO NOVO}

As memórias dos entrevistados sobre a malária reportam-se, sobretudo, às décadas de 40 a 60 do século passado; contudo, o interesse do Estado português por esta doença remonta ao início da década de 30. O destaque dado pelos médicos à malária - classificada como uma doença rural -, bem como a concentração das intervenções dos serviços antissezonáticos ${ }^{8} \mathrm{em}$ concelhos dominados pela atividade agrícola, particularmente pelo cultivo do arroz (Landeiro 1942; Landeiro e Cambournac s.d.), refletiam as tendências da saúde internacional e a lógica das trocas científicas que caracterizou o período entre as guerras, mas também as condições sociopolíticas em Portugal, nos anos 30 do século XX.

8 A designação "antissezonáticos”, oficialmente atribuída aos serviços dedicados ao tratamento e controlo da malária, resultou da palavra "sezonismo", adotada por Ricardo Jorge, cerca de 1903, como a melhor para nomear a malária (IGSS 1903). 
Nos vales do Tejo e Sado, a composição dos grupos sociais era fortemente influenciada pela posse e acesso à terra, destacando-se a diferenciação entre proprietários e trabalhadores rurais - que tem sido analisada no contexto dos "campos do sul" (Cutileiro 1977; Rosas et al. 1994; Carmo 2007). A estrutura fundiária - com presença de grandes propriedades -, os modos de exploração da terra e a organização social hierarquizada e desigual que lhe estava associada mantiveram-se até aos anos 60, ainda que com algumas alterações no pós-guerra (Baptista 1993).

A afirmação da ideologia do bucolismo rural, do Portugal fundamentalmente agrário (Rosas 2001), resistiu às tentativas reformistas de Rafael Duque, ministro da Agricultura entre 1934 e 1940 e ministro da Economia entre 1940 e 1944 (Amaral 1994; Rosas 1991; Baptista 1993), assim como à influência dos grupos industrialistas que, depois da II Guerra Mundial, adotaram uma posição crítica à orientação económica do país (Amaral 1994). Persistia a influência política dos proprietários rurais que, por meio da sua ligação aos poderes local e central, bem como pela sua influência nos grémios agrários, procuravam defender os seus interesses, tentando travar a modernização (Amaral 1994; Rosas et al. 1994).

A centralidade ideológica e económica do mundo rural refletiu-se na criação da Estação Experimental de Combate ao Sezonismo de Benavente, em 1931, assinalando o arranque de um serviço dedicado ao estudo, profilaxia e controlo da malária (Faria 1934). Estudar a malária em Portugal, criar estruturas para o seu controlo e tratamento, intervir na regulação da cultura do arroz resolveria o problema da articulação entre interesses económicos e saúde pública, servindo ao mesmo tempo os interesses nacionais.

Também as tendências da investigação e ação em saúde, promovidas e veiculadas pela Organização de Higiene da Sociedade das Nações (OHSDN), criada em 1922, bem como pela Fundação Rockefeller, reforçavam a importância da saúde rural e do controlo da malária. ${ }^{9}$ A OHSDN inscrevia-se na conjuntura política, social e económica do período entre as guerras, congregando diversos projetos e interesses em torno da promoção da saúde, compreendida numa perspetiva transnacional (Borowy 2009). Um dos projetos da OHSDN foi precisamente a saúde rural e a defesa da assistência na saúde para todas as populações (Société des Nations 1931; Borowy 2009). Na articulação entre, por um lado, interesses políticos e económicos e as conveniências profissionais dos

9 Ricardo Jorge foi inspetor-geral de saúde de 1899 a 1911, diretor-geral de saúde de 1911 a 1928 e ocupou o cargo de vice-presidente do Comité de Higiene da Sociedade das Nações, ligado à OHSDN (Coelho 1961); Nicolau Bettencourt, do Instituto Bacteriológico Câmara Pestana, em Lisboa, e responsável pela Estação Experimental de Combate ao Sezonismo de Benavente, participou em missões de estudo patrocinadas pela OHSDN, com financiamento da Fundação Rockefeller (Bettencourt 1924); Fausto Landeiro e Luís Figueira, diretores da Estação Anti-Sezonática de Benavente, estudaram malariologia na Alemanha, na Jugoslávia e em Itália, com bolsas da OHSDN (Figueira e Landeiro 1931). 
médicos, na esfera nacional e, por outro lado, as propostas da OHSDN, servindo tanto esforços de cooperação como competições de fundo nacionalista entre os Estados, os médicos portugueses procuravam legitimidade para as reformas propostas na área da saúde pública.

Este foi o ponto de partida dos serviços antissezonáticos, organizados na dependência da Direção-Geral de Saúde e que apenas em 1938 foram regulamentados, com a criação da Direção dos Serviços Anti-Sezonáticos (República Portuguesa 1938), num diploma legislativo que revia as condições da produção do arroz. ${ }^{10}$ Formando os malariologistas que haveriam de integrar estes serviços e centralizando a investigação em malariologia em Portugal, foi ainda criada, em 1934, pela Divisão de Saúde Internacional da Fundação Rockefeller, a Estação para o Estudo do Sezonismo, em Águas de Moura (Landeiro 1942). Em 1939, quando se tornou propriedade do Estado português, a estação passou a designar-se Instituto de Malariologia (CMP 2001).

Aos Serviços Anti-Sezonáticos competia intervir na concessão de licenças para a instalação de campos de arroz. Cabia-lhes ainda rastrear os casos de malária entre a população das áreas endémicas, tratar os casos detetados e promover métodos profiláticos, como o uso de redes mosquiteiras. Os postos e estações antissezonáticos eram dirigidos por um médico malariologista e contavam ainda com o trabalho de "visitadoras", a quem cabia o registo e monitorização dos doentes, inclusivamente nos seus domicílios, a distribuição e administração de medicamentos. Desde 1934, estes serviços passaram a ser financiados pelo Estado e pela Comissão Reguladora do Comércio do Arroz, que cobrava uma taxa específica para este efeito aos produtores deste cereal (República Portuguesa 1934). Quer os estudos epidemiológicos quer a legislação formalizavam a ligação centenária entre a malária e os arrozais.

10 O DL n. ${ }^{\circ}$ 28.493, de 19 de fevereiro de 1938, criava a Direção dos Serviços Anti-Sezonáticos com as estações de Montemor-o-Velho, Benavente, Idanha-a-Nova e Alcácer do Sal e os postos de Pocinho, Soure, Ponte de Sor e Azambuja (República Portuguesa 1938). Mas alguns destes estabelecimentos estavam já em funcionamento: a estação de Benavente abriu em 1931, a de Alcácer do Sal em 1932, a de Montemor-o-Velho em 1933; o posto do Pocinho (no Douro) e o de Azambuja (inicialmente funcionando como dispensário) em 1934. Em 1945, o decreto-lei que reformava os serviços de saúde e assistência estabelecia que os Serviços Anti-Sezonáticos passavam a designar-se Serviços de Higiene Rural e Defesa Anti-Sezonática, designação que mantiveram até à sua extinção, em 1984 (República Portuguesa 1945, 1984). Estes serviços foram alargando o escopo da sua ação a outras doenças parasitárias e às zoonoses, particularmente desde que, a partir do início da década de 50, se verificou um decréscimo significativo da malária endémica. Os postos, estações e dispensários antissezonáticos proporcionavam atendimento médico e tratamentos gratuitos, tal como outros (raros) estabelecimentos de saúde diretamente administrados pela Direção-Geral de Saúde, como era o caso dos dispensários de higiene social, criados para o controlo da sífilis e das doenças sexualmente transmissíveis ou "doenças venéreas" (Lemos 1932; DGS 1944). Contudo, os serviços antissezonáticos estavam vocacionados para patologias específicas, não lhes competindo prestar cuidados de saúde generalistas, nem tendo recursos para tanto, o que suscitava críticas entre alguns dos seus médicos (DGS 1944). 
A intervenção dos Serviços Anti-Sezonáticos na saúde rural poderia ser apelativa para o projeto do regime político emergente, que elegera os campos, sua população e "tradições" como elementos centrais da retórica sobre a identidade nacional portuguesa (Leal 2000; Melo 2001; Rosas 2001). Contudo, o Estado Novo, em consolidação, adotava uma orientação corporativa, estabelecida na Constituição de 1933 (Lucena 1976; Rosas e Brito 1996; Ferreira 2008). Apesar do seu caráter controlador, intervencionista e dirigista, dando forma a um corporativismo estatal, o regime privilegiou a economia (Ferreira 2008), sendo as questões sociais e de saúde relegadas, em larga medida (e como em outros contextos europeus de regimes democráticos), para a esfera da iniciativa privada, dos princípios "tradicionais" da caridade cristã (Pimentel 2000; Costa 2009). A organização de um serviço de saúde pública eficiente e abrangente, orientado pelo paradigma da medicina social e preventiva (Faria 1934) teve, por isso, resultados modestos.

A ação continuada dos postos, estações e dispensários antissezonáticos, desde o início dos anos 30, e a sua integração no quotidiano das populações rurais, o uso de inseticidas de ação remanescente, a partir do final da década de 40, as transformações (lentas mas irreversíveis) nas formas de exploração da terra, a progressiva mecanização da agricultura, nomeadamente da orizicultura, e a introdução da monda química, que reduziam o número de trabalhadores necessários (Baptista 1993), bem como as paulatinas transformações económicas e sociais, mais notórias a partir da década de 60, nomeadamente o êxodo rural (Costa 2009) são fatores a considerar na ecologia da malária, para além de outros fatores climáticos e ecológicos, desaparecidos das considerações médicas sobre as variações na incidência desta doença, mas que devem ser ponderados na convergência de fatores que ditaram o seu desaparecimento em Portugal, na década de 60.

A década de 50 anunciou transformações, como "a industrialização, a urbanização, a terciarização” (Rosas 2001: 1051). Mas a ideologia nacionalista, corporativista e ruralista resistia como discurso oficial legitimador das orientações do Estado na administração das diversas esferas da vida pública, incluindo a saúde. A influência inevitável de modelos internacionais onde dominavam as ideias de progresso, desenvolvimento, bem-estar e igualdade, veiculados pelas relações económicas com o exterior, pela emigração e pelas organizações internacionais de cariz diverso - entre as quais a Organização Mundial de Saúde (OMS), onde Portugal estava representado desde a sua criação, em $1948^{11}$ influenciava os debates e tendências sociais, apesar do conservadorismo e autoritarismo políticos.

11 A OMS organizou cursos internacionais de malariologia no Instituto de Malariologia de Águas de Moura, durante a década de 50 (Cambournac 1990). Francisco José Cambournac, diretor deste instituto entre 1939 e 1954, foi diretor do gabinete regional para África, da OMS, entre 1954 e 1962. 
Contudo, o regime permanecia resistente ao estatismo e à "socialização" da assistência e da saúde, ainda que esta fosse a tendência internacional (Costa 2009). A criação do Ministério da Saúde e Assistência, em 1958, foi uma tentativa de ordenar e coordenar a multiplicidade de organismos e instituições públicas e privadas ligadas a estas áreas. Mas, nas bases da política de saúde e assistência de 1963, o Estado continuava a ter funções de planeamento, orientação e coordenação, exercendo "ação meramente supletiva em relação às iniciativas e instituições particulares” (República Portuguesa 1963: 969).

Apesar do grande incremento das caixas de previdência, a população rural continuava a ser a mais desprotegida. Na orgânica corporativista, as casas do povo - congregando proprietários, rendeiros e assalariados - deveriam garantir a assistência social (apoio em caso de desemprego, subsídio em caso de doença e na velhice), de saúde e reduções na compra dos medicamentos (Lucena 1976). Os indivíduos nelas inscritos estavam obrigados ao pagamento de quotas mensais, estabelecidas de acordo com os seus rendimentos. No entanto, as casas do povo nunca cobriram a totalidade das freguesias rurais (Lucena 1976). Para além disso, atendendo aos baixos salários dos trabalhadores rurais, poucos de entre eles conseguiam manter as suas quotas em dia, acabando por não poder beneficiar dessas condições (Cutileiro 1977).

Os postos, estações e dispensários antissezonáticos continuaram, por isso, a gozar de grande popularidade nas regióes rurais onde existiam, estendendo, em alguns casos, a sua ação a outras dimensões da assistência na saúde - nomeadamente a saúde infantil (Freire 1952). É também com "a cooperação, no domínio das suas atribuições específicas, dos serviços de higiene rural e defesa antissezonática" que o governo conta, para a sua incumbência de "prestação de assistência médica às populações rurais", de acordo com o "plano de desenvolvimento e generalização da proteção social dos trabalhadores rurais e suas famílias" (República Portuguesa 1963: 971).

\section{MEMÓRIAS DO TRABALHO RURAL:}

"MAL ROUPADO, MAL CALÇADO, MAL COMIDO"

Os fatores sociopolíticos, aqui brevemente enunciados, determinavam as condições de vida e trabalho no campo e, consequentemente, condicionavam a incidência da malária, o seu peso e relevância no quotidiano das populações mais afetadas, traduzidos no modo como estas atuavam em face da doença.

A centralidade do trabalho nas narrativas dos entrevistados confere protagonismo ao corpo, sem que este seja diretamente mencionado. É um corpo em ação, representado como força de trabalho, percebido intermitentemente, quando se fala de padecimentos físicos que o tornam temporariamente mais presente, na sua materialidade. Os sintomas da malária desencadeiam um 
desses momentos de tomada de consciência do corpo; mas esta doença aparecia em último lugar na hierarquia das preocupações, sendo os seus sintomas sobretudo relevantes por interferirem nas rotinas, impedindo o desempenho de tarefas indispensáveis à sobrevivência dos indivíduos. A partir do momento em que os sintomas debilitantes desapareciam, permitindo aos indivíduos prosseguir o seu ritmo quotidiano, a malária perdia importância.

Ilustrativo da centralidade do corpo ativo e instrumental e de como esta conceção condicionava e relativizava a relevância da malária, no discurso dos entrevistados, é o caso do trabalho feminino. As memórias das mulheres entrevistadas estavam sobretudo associadas ao trabalho no arrozal. Até aos anos 60 do século XX, grande parte do trabalho das diferentes fases da cultura do arroz era manual. Esta era a principal ocupação de quase todas elas, por ser a que requeria maior número de braços - inclusive grupos de trabalhadores migrantes ${ }^{12}$, ao longo das várias fases de preparação, plantio, monda e ceifa daquele cereal.

"'Tava tudo charruado com os tratores e depois era tudo direito com as grades de pau - havia umas grades de pau com uns ferros. E depois semeava tudo com um semeador - que já havia nesse tempo também semeadores ou à mão, os homens, e depois a gente [mulheres] a enterrar com a enxada. Descalças, com geadões branquinhos; chegámos a perder [salário] para ir para o fogão aquecer os pés. A gente mal chegasse um bocadinho atrasado era logo descontado" [Juliana, Arez, 2006].

“J — Tinha um motor de maneira a tirar água para dentro do arroz; o peixe vinha, ficava nos canteiros; depois faltava-lhe a água [morria]. $\mathrm{Na}$ ceifa, andava a gente a ceifar e aquele cheiro do peixe.

$\mathrm{E}-\mathrm{E}$ a gente com um pé de cada lado para não pisarmos a espinha dos peixes... e aquele cheiro pelo nariz?!..." [Elvira e Josefa, Azambuja, 2006].

O imperativo do regresso das mulheres ao lar, subjacente à ideologia e legislação do Estado Novo sobre a família como base da sociedade e economia nacionais (Gorjão 2002: 97-101), não fazia parte do universo das assalariadas rurais. Para estas, aos trabalhos do campo juntavam-se as tarefas domésticas, feitas no regresso a casa, depois de uma jornada de trabalho. Essas tarefas envolviam o arranjo da casa, a preparação da refeição noturna da família, a

12 Os ranchos de trabalhadores rurais migrantes que sazonalmente se deslocavam sobretudo para os campos do sul desempenhavam vários tipos de trabalhos, mas eram mais frequentes nas épocas de maior exigência de mão de obra na produção cerealífera, nomeadamente durante as épocas das mondas e da ceifa. Eram medicamente considerados elementos-chave da propagação da malária (Landeiro e Cambournac s.d.). 
cozedura do pão e a preparação dos alimentos que levariam para mais um dia de trabalho, a lavagem da roupa da casa ou para fora, como suplemento ao rendimento familiar, a higiene das crianças (lavar, pentear, catar). Mas a rudeza do trabalho feminino no campo e o modo como interferia com o cuidado dos filhos, impelindo muitas a levarem as crianças consigo durante a jornada de trabalho, foi também rememorada com emoção, como símbolo das agruras que passaram e que levavam algumas a lamentar (revelação feita com algum embaraço) cada gravidez.

Por seu lado, os homens referiram uma grande variedade de trabalhos, dos quais se distinguem, em relação às tarefas mencionadas pelas mulheres, a extração de cortiça, a guarda de gado e o trabalho com gado bravo (na região de Azambuja). As suas preocupações eram experimentadas a partir dos imperativos do chefe de família, que devia prover à alimentação e proteção da mulher e dos filhos. Para além dessa preocupação, dominaram também as narrativas sobre a precariedade do trabalho, a sua escassez periódica (equivalente a ameaça de fome) e a dureza das condições em que se trabalhava:

"E eu, no fim de resto, acabou-se aqui essa coisa do arroz, isto aqui não havia trabalho nenhum e eu o que é que pego? A minha mulher fica em casa mais as minhas duas filhas, já grandinhas, e eu sem saber o que é que havia de fazer à minha vida. Tínhamos nessa altura uma criação; a minha mulher fritou-me uns ovinhos [...] com bacalhau desfiado, um bocadinho de pão, dentro de um talaguinho e fui além apanhar o comboio, ali à estação de Vale de Guizo [...] fui para perto de Algeruz pedir trabalho pr'às vinhas" [Manuel, Vale de Guizo, 2006].

"Então a gente começávamos os viveiros [de arroz] no mês de março [...]; e naquele tempo não havia botas de borracha. Era com os pés a partir o gelo. [...] 'tava tanto frio, fomos montar os viveiros que era para semear o arroz, o gelo era tanto que as pessoas começaram a desmaiar. E o capataz, 'vá tudo cá para fora'. Fomos então desmoitar lá para o montado, arrancar mato" [José, Alcácer do Sal, 2006].

O corpo é revelado e definido nas narrativas das memórias sobre "ter malária", pelos seus padecimentos e pelas práticas rotinizadas/naturalizadas e generificadas ligadas aos múltiplos trabalhos da terra, assim como às obrigações sociais dos indivíduos, especialmente à sua ação convencionada no grupo familiar. Este habitus presente nas narrativas é fundamental para compreender a malária tal como foi contada pelos entrevistados. Como adiante veremos, nas memórias dos antigos trabalhadores rurais, essas práticas interrompidas ou subvertidas pela malária condicionavam as ações que esta desencadeava, numa acomodação mútua. 


\section{A COMIDA, A CASA E A MALÁRIA}

No presente, a proposta de abordagem "sindémica" da antropologia médica às questões de saúde realça a importância da malnutrição, como um dos elementos mais relevantes nas sinergias entre diversas patologias - entre as quais a malária - e os contextos sociais que as enquadram (Singer e Clair 2003). A nutrição foi um dos temas de eleição dos estudos desenvolvidos no âmbito da OHSDN (Borowy 2007, 2009). Nesta linha, foi uma matéria estudada quer pelos malariologistas do Instituto de Águas de Moura, quer pelos médicos dos postos e estações antissezonáticos (Hill e Cambournac 1941; Cambournac e Simões 1944; Ramos 1944; Mira 1948), embora não se encontre, nesses breves estudos, referências diretas à relação entre nutrição e malária.

Para os entrevistados, a relação entre alimento e malária surgiu antes, de maneira inusitada, na referência aos "grandes apetites" que a doença provocava e que, quando satisfeitos, podiam resultar em curas definitivas. Assim, os entrevistados falavam em desejos súbitos de comer uma caixa de sardinhas, pão com linguiça, bacalhau frito com alho, de beber vinho diretamente da pipa, de comer laranjas. Não se tratava de desejos por comidas "exóticas", mas antes por alimentos a que as pessoas não acediam regularmente ou em quantidade. Os apetites expressavam-se em relação à abundância, ou na variação da dieta. Nos episódios narrados, os desejos dos enfermos foram sempre satisfeitos. Como se a doença representasse um período de exceção, dando ao doente um estatuto especial. Estes desejos conferiam à malária o caráter de pretexto para a transgressão de limites impostos pela condição social dos indivíduos, talvez no ponto (a alimentação) em que esses limites eram, ao mesmo tempo, mais significativos na hetero e autorrepresentação da classe dos assalariados rurais, mas também mais facilmente superáveis, ante a carência de recursos.

A fome era uma noção variável nos discursos dos entrevistados. Avaliando retrospetivamente o que comiam, consideravam que passavam fome porque o alimento era pouco e pouco variado - dominavam o pão, base da alimentação, o toucinho, as couves e as azeitonas. Contudo, parece também evidente que, na época, fome era a total ausência de alimento para si e para a família. Mas as referências à comida e a descrição - por vezes compungida e carregada de diminutivos ("açordinha”, "sopinha”, "sardinhazinha”), significando insuficiência - daquilo que se comia serviam sobretudo para caracterizar o passado de escassez e pobreza, marcado pela iminência da fome. Por outro lado, os discursos sobre o que se comia revelaram também as ambiguidades da memória e o peso do presente na sua constituição: apesar da omnipresente ameaça da fome, consideravam-se dominantemente "sadios"; e nada se compara ao sabor da comida de antigamente.

Juntavam-se às narrativas sobre a alimentação monótona e pouco abundante as descrições das casas ou das condições em que habitavam. As casas surgiram 
igualmente como elemento narrativo usado para ilustrar a naturalização da pobreza, traduzida na naturalização da sua exiguidade, precariedade e despojamento, retrospetivamente avaliados. Aqueles que viviam em habitações pertencentes aos patrões tinham casas de pedra cobertas de telha. As habitações próprias ou arrendadas podiam ser igualmente de pedra e telha mas podiam também ser de materiais improvisados ou mais simples, como taipa, madeira, caniços, sacos de arroz, etc.

“[...] aquela [cabana] da minha mãe só tinha um quarto... era dividida, uma parte era o quarto, tinha duas camas, que era onde eu dormia com a minha irmã $[\ldots]$ e tinha a cama da minha mãe. O que fazia o outro quarto era a minha mãe à noite punha a colcha assim por cima do leito da cama - era da espécie que tinha os leitos assim altos - é que, faça de conta, que dividia outro quarto. E tinha então a casa de fora onde é que ela tinha alguma coisita - pouca - tinha... onde puseram ali uma mesa com uma calçadeirazinha em cima e umas malas com a roupa e... era assim!... E tínhamos então outra cabana à parte onde fazia a cozinha, por causa dos fogos. Toda a gente tinha outra cabanazita [...] A gente era umas cabanas mas era tudo... era por dentro... fora, caniços, e por dentro eram forradas com sacos, cosia-se os sacos uns aos outros e depois forrava-se as paredes todas, depois era tudo caiadinho com cal e tava tudo branquinho lá por dentro" [Dionísia, Montevil, 2006].

Os grupos de trabalhadores migrantes eram alojados naquilo a que os entrevistados chamaram "casões" ou "quartéis". Tratava-se de edifícios amplos, albergando várias dezenas de pessoas, onde se cozinhava e dormia. Estes abrigos foram providenciados, entre outras razões, por força do mesmo decreto que criou os serviços antissezonáticos (República Portuguesa 1938). Iam ao encontro das conclusões dos estudos malariológicos, que apontavam a precariedade dos abrigos dos trabalhadores rurais como um fator determinante na incidência da malária (Cambournac 1938; Hill 1938). No entanto, as condições em que se encontravam os abrigos para os trabalhadores migrantes nem sempre obedeciam ao estabelecido pela lei, a avaliar pelos comentários de alguns dos diretores das estações e postos antissezonáticos (DGS 1944: 188).

A referência ao problema da fome iminente ou manifesta e a descrição das casas permitem-nos compreender, por um lado, porque o problema da subsistência e vulnerabilidade dos indivíduos secundarizava a malária, na hierarquia das suas prioridades quotidianas; por outro lado, permitem-nos confrontar algumas abordagens médicas sobre nutrição e habitação, direta ou indiretamente equacionadas em relação com o problema da malária (Cambournac 1938; Hill 1938; Hill e Cambournac 1941; Cambournac e Simões 1944; Mira 1948). Desse confronto resultam alguns desajustes entre as conclusões, recomendações 
e práticas médicas, e as práticas, hábitos alimentares e características das casas dos trabalhadores rurais, descritos nos depoimentos dos entrevistados. "Casa e comida" eram fortemente marcadas pela desigualdade e pela pobreza, enraizadas em fatores estruturais impossíveis de transformar à força de argumentos sanitários, como o da necessidade de uma dieta variada e suficientemente nutritiva ou o imperativo de usar mosquiteiros nas camas e redes metálicas nas portas e janelas.

As memórias revelaram rotinas alimentares decorrentes tanto do hábito quanto da carência ou da partição do tempo do trabalho, bem como da socialização durante esse tempo; revelaram também que nem todas as "casas" eram de alvenaria, com portas e janelas convenientemente instaladas, e nem toda a gente dormia sempre numa cama: ${ }^{13}$

"[...] sabe onde é que a gente dormia para descansar alguma coisa? Em cima das árvores, como os pássaros. Púnhamos uns paus atados com uns arames ou com cordas e depois aquela prancha de cortiça e púnhamos lá fetos, que era uma erva, pronto... assim é que a gente dormia, por causa dos mosquitos que não deixavam a gente descansar, nesse tempo" [José, Alcácer do Sal, 2006].

O protagonismo dado, nos trabalhos médicos, a práticas preventivas desajustadas às condições materiais das moradas dos assalariados rurais, ou às condições em que estes pernoitavam, decorria do imperativo de controlo estratégico e científico da malária que, segundo os modelos internacionais, elegia as habitações como os locais privilegiados de infeção do homem pelo mosquito e vice-versa (League of Nations 1927; Christophers e Missiroli 1933). Quem dormia ao relento não entrava na conta do "risco de infeção", pelo que não cabia na alçada do controlo sanitário; como não contavam os mosquitos, escorpiões e outros insetos que os atormentavam. De resto, também para os entrevistados, dormir "a campo", dormir "aos mosquitos" não era relevante do ponto de vista da malária, mas era ilustrativo da miséria e das provações físicas pelas quais passaram.

Quer consideremos as memórias sobre o que se comia quer sobre a casa onde se habitava, estamos perante descrições de gestos naturalizados e a materialidade do quotidiano, práticas (competências, técnicas, hábitos) que, no discurso dos entrevistados, se relacionavam direta ou indiretamente com a malária - não no sentido de causa e efeito, mas como enquadramento de referência da existência e relevância desta doença nas suas experiências individuais

13 O problema das condições de vida dos trabalhadores rurais, nomeadamente a impossibilidade de instalar a proteção mecânica em algumas casas, também surgiu nos trabalhos dos médicos dos serviços antissezonáticos, que tinham contacto mais próximo com as populações (DGS 1944; Ramos 1944). 
e coletivas. O sofrimento a que resumiam a sua descrição da vida passada expressava-se através do corpo - o que se comia, como e onde se abrigavam, a sua relação com o meio envolvente.

\section{AS SEZÕES}

É no contexto até aqui apresentado, cruzando experiências físicas, papéis sociais dos indivíduos, ambiente natural, discurso e ação médicos, que devemos perceber as definições da causa e transmissão da malária, bem como as descrições dos modos de a curar, conforme relatadas pelos entrevistados.

Nestes relatos, a corporeidade da doença manifestou-se quer na expressividade da descrição dos sintomas, acompanhada pela sua dramatização, quer pela caracterização dominante da malária como impedimento ao desempenho das ações social e individualmente esperadas, interrompendo o curso "normal" do tempo. Mas era uma interrupção transitória, tendo a duração de algumas horas distribuídas por alguns dias alternados. Por conseguinte, a malária era uma doença intermitente. A descrição dos sintomas e da sua regularidade quase matemática tem implícita a sua popularização, permitindo a imediata caracterização e identificação da doença, sem mediação da autoridade do conhecimento médico. Por outro lado, a descrição de sintomas, da progressão e periodicidade das febres, reflete também séculos de teorização médica sobre essas manifestações, onde as "febres intermitentes" tinham protagonismo (Wilson 1993), e em que, apesar da especialização do saber dos médicos, estes partilhavam com os seus pacientes um conjunto de referências e sinais que vinham da experiência física e da observação direta.

"D - Aquela febre, aquela febre que se tinha, o corpo tremia todo.

M - É que a gente queria suster a tremura e não era capaz; batia mesmo o queixo com a febre" [Domingos e Matilde, Azambuja, 2006].

"A gente ia para o trabalho [...] ao fim de uma hora ou coisa assim começavam a... em pleno verão!, a tremer todos com um frio terrível e a lançar fora; perdia a força, tínhamos que ir embora para casa" [Dâmaso, Vale de Guizo, 2006].

"E havia as sezões, nesse tempo chamavam-lhe as sezões... e era dia sim, dia não: trabalhávamos hoje e amanhã descansávamos; mas descansávamos a sofrer, não deixavam trabalhar [risos]" [José, Alcácer do Sal, 2006].

Segundo as definições biomédicas atuais, o mosquito Anopheles é o único vetor da malária humana. Ao explorar a questão da causa da malária nas entrevistas, encontrei explicações mais ou menos elaboradas mas raramente 
restritas à conceção biomédica, ainda que clara e incontornavelmente influenciadas por ela. As referências aos mosquitos não se prenderam exclusivamente - nem mesmo especialmente - com o seu papel de vetor da malária; os mosquitos foram sobretudo definidos como um incómodo constante, a que era difícil escapar, por serem em grande número e impossíveis de controlar, tanto no exterior como no interior das casas.

Os insetos que faziam parte do quotidiano das pessoas surgiram amiudadas vezes nas entrevistas, ilustrando a pobreza e a diferença abissal entre a vida passada e o presente, o "atraso" em que se vivia. Nesta lógica, as conceções sobre a desinsetização, levada a cabo pelas brigadas dos serviços antissezonáticos nas habitações, não coincidiam com o propósito que os serviços atribuíam a essas ações, havendo quem dissesse que "o DDT era para desinfetar as casas" ou que "era para as pulgas e os percevejos" [Ilda e Marcolina, centro paroquial de Azambuja, 2006]. Um antigo funcionário dos serviços antissezonáticos explicou que as pessoas deixavam as brigadas de desinfeção entrar nas suas casas "porque julgavam que aquilo matava... mais por aquilo matar as moscas. Nunca ninguém pensou nos mosquitos [...] deixavam mais era a luta contra as moscas" [Oliveira, Benavente, 2007].

Os mosquitos não eram, portanto, particularmente diabolizados por ligação com a malária, até porque não eram, regra geral, a única causa reconhecida da doença. As narrativas dos entrevistados revelaram a malária produzida a partir das experiências individuais e coletivas, bem como das relações com o meio, nomeadamente através do trabalho e dos gestos, técnicas e tempo que lhe estavam associados. Os discursos expressaram o sincretismo ou ecletismo das representações da etiologia da malária, associando ao papel dos mosquitos e dos arrozais outros discursos médicos pré-bacteriológicos sobre ares infetados, a podridão da água, o calor e a putrefação de matérias vegetais:

"As sezões foram talvez causadas pelos arrozais. Que a gente andávamos semanas e semanas metidos na água; aquela água aquecia com o calor, não é? e além disso bebia-se muitas águas impróprias. Bebia-se águas da borda da reveza [...] águas impróprias!... e dali é que se deu as sezões, pois foi; derivado à alimentação e às águas - foi mais às águas. Depois, aquilo criava muitos mosquitos e os mosquitos é que transmitiam as sezões" [José, Águas de Moura, 2006].

"A origem das sezões era as águas estagnadas [...] pântanos, o arroz. Não sei se vocês se lembram bem, naquele tempo, nós andávamos a mondar o arroz, fazíamos [buracos] e enterrávamos no charco, [aquilo] apodrecia e gerava a podridão das águas. É isso e mais nada. Eu estive lá três anos, foram os piores anos que tive na minha vida. Só não morri foi porque não calhou" [Manuel, Benavente, 2005]. 
Na história da medicina, as febres estiveram no centro de alguns debates sobre a natureza das doenças e os processos patológicos, dadas as muitas formas que podiam assumir (Bynum e Nutton 1981; Porter 1999). Enquanto manifestação de infeções miasmáticas, produzidas pelas "exalações venenosas exsudadas por matéria animal em decomposição, vegetação apodrecida e águas paradas" (Porter 1999: 259), as febres intermitentes (associadas à malária) foram consideradas como efeito dos terrenos pantanosos e alagadiços, entre os quais se podiam contar os arrozais (Sanches 1757; Chaves 1790). Estas conceções - muitas delas ancoradas na observação e descrição detalhada de sintomas terão sido incorporadas na sabedoria popular, adequando-se às experiências individuais e coletivas e dilatadas por outras explicações médicas para a causa específica de determinadas doenças febris, que passavam pela ingestão de “águas impróprias", como, por exemplo, no caso da febre tifoide (Wilson 1993). Daqui resultaram representações ecléticas e holistas da malária (relacionando o corpo com o seu meio envolvente) que perduraram até ao presente.

\section{CURAR AS SEZÕES}

A busca da cura para a malária revelou o mesmo ecletismo encontrado nas considerações sobre a sua causalidade, mesmo para quem reconhecia aos serviços antissezonáticos o mérito de terem conseguido fazer desaparecer a doença. Por ser fundada na necessidade física, pragmática e imediata de restabelecimento da capacidade de trabalho e de cessação do mal-estar, para os antigos assalariados rurais, a conceção do tratamento da malária não coincidia exatamente com a noção de cura preconizada pelos médicos. Esta obedecia a modelos cientificamente fixados que implicavam a inexistência de parasitas no sangue, verificável apenas por técnicos especializados, assim como um regime de toma dos medicamentos adequado a este fim. Para os entrevistados, os parasitas eram irrelevantes ou nem sequer mencionados. Curar a malária era fazer desaparecer os sintomas causadores de desconforto físico e exaustão, que os impediam de fazer o seu trabalho:

“[...] aquilo fica no sangue, o paludismo fica no sangue. Pronto, começa-se a governar mas se for fazer umas análises acusa logo o paludismo. Mas a pessoa governa-se" [João, Rio de Moinhos, 2006].

Para este efeito, serviam os remédios e chás preparados em casa, tomados por sugestão de vizinhos e parentes, recursos terapêuticos que eram propriedade do grupo de pertença dos entrevistados, saberes produzidos e reproduzidos dentro desse grupo e mais ou menos imediatamente acessíveis a todos. Mas serviam também, sem contradições ou incompatibilidades, os medicamentos distribuídos gratuitamente no "posto das sezões". Assim, as entrevistas revelaram 
a familiaridade com o quinino, referência dominante entre os remédios que recebiam no posto, mas também com outros medicamentos antimaláricos sintéticos, que foram introduzidos a partir dos anos 30 .

As entrevistas sugerem que se aceitava os serviços oferecidos pelos postos antissezonáticos, incorporando-os no reportório de práticas associadas à malária. A relação com o "posto das sezões" era assim regida segundo a vivência do tempo dos trabalhadores rurais e segundo a sua perceção da doença, caracterizada por sintomas distintivos que todos reconheciam, autodiagnosticando-se. Procuravam dos serviços antissezonáticos sobretudo o alívio dos sintomas, para retomarem as suas rotinas. As características da malária, permitindo várias reinfeções e mesmo recidivas com meses de intervalo, em resultado de terapia inadequada ou interrompida, a dificuldade em aceder rapidamente ao "posto das sezões", bem como a centenária incorporação do uso de plantas nos tratamentos caseiros do mundo rural, legitimavam também o pluralismo terapêutico.

Em Benavente, Azambuja, Alcácer do Sal e aldeias deste concelho, a marcela dominava entre as ervas usadas "contra as sezões". Trata-se de uma planta rasteira de flor miúda amarela, que nasce nas charnecas e matas. Com a flor fazia-se um chá, adjetivado como "muito amargoso". Outras plantas referidas foram a erva-férrea, o piorno, a raiz de alteia e a erva "seca ossos". O paralelismo entre o amargo do chá de marcela e de piorno em relação ao amargo do quinino é evidente e não será casual:

"Para as sezões era, olhe, era água da marcela, que aquilo parecia veneno!... ai, nunca fui capaz de beber; para a febre, ai mas aquilo era tão amargoso, tão amargoso, mas tinha de ser coisas amargosas para combater as sezões. E os tremoços de molho e beber aquela água que também era muito amargosa, eu sei lá..." [Juliana, Arez, 2006].

"A gente cá fazia era um chá da marcela e chá da erva-férrea, as nossas mães; depois punham ali na rua, dentro de uma tigela, coava aquilo e dava... e púnhamos na rua (a minha mãe tinha uma janela), chamavam as nossas mães - a gente agora já não diz isso - a asserenar. Deixavam na boca dos potes e depois de manhã, em jejum, bebíamos aquilo, aquela água da marcela. Era muito amargosa!..." [Maria, Vale de Guizo, 2006].

A predominância desta característica comum - o amargor - indicia uma eventual identificação entre o facto de serem amargas e as propriedades febrífugas reconhecidas a todas essas substâncias; ser amargo era a marca da propriedade antipirética, era o indício legitimador das ervas, assimilando-as ao quinino, o que sugere a influência da medicina e a centralidade dos acessos febris e sua periodicidade na identificação e definição da malária. 
Para além das plantas e chás, foram também mencionadas outras mezinhas, combinando vários ingredientes: "o rabo de bacalhau de molho em água e aguardente”, bebido de manhã em jejum [Domingos, Azambuja, 2006]; “aguardente [...] com açúcar" [Maria José, Azambuja, 2006]; "vinagre, com um dente d'alho a asserenar" bebido no dia seguinte em jejum; "pólvora com aguardente" [José, Alcácer do Sal, 2006]. A ingestão destes preparados, à base de alho, aguardente, vinagre ou pólvora resultava em abundante sudação, associada, na medicina pré-bacteriológica e nas práticas populares, ao processo de purificação do sangue, de eliminação dos venenos causadores da doença manifestada pela febre. Mas, nos discursos dos entrevistados, estas práticas não desencadeavam reflexões ou considerações sobre a sua ação no corpo; foram sobretudo apresentadas como resposta a uma necessidade imediata de cessar o mal-estar.

A malária surgiu, assim, caracterizada pela corporeidade dos sintomas, pelas limitações das rotinas corporais de trabalho e pela pluralidade das terapêuticas empregadas no seu tratamento. Era uma malária pragmatizada, sem relevância social para além das sensações, da ordem interrompida e das práticas desencadeadas. Por isso, para os entrevistados, as noções de risco e prevenção da malária não tinham significado. Esta não tinha valor social como entidade específica, discreta (no sentido médico), autónoma do momento em que era sentida no corpo e das implicações no quotidiano; mesmo quando se reconhecia que "ficava no sangue". Era uma fatalidade para a qual "não havia resguardos"; tal como a sua condição social, "era o que tinha de ser". E foi com o mesmo pragmatismo que os entrevistados falaram sobre o papel do "posto das sezões" nas suas experiências da malária.

\section{O "POSTO DAS SEZÕES"}

A multiplicidade de recursos socialmente legitimados para fazer frente à malária expressou-se na inexistência de contradições entre a familiaridade dos entrevistados com as estações e postos antissezonáticos, e as afirmações dos que diziam que "usava-se pouco ir ao médico" e que "a gente cá há uns anos atrasados era quase tudo à base mais de ervas". Os postos, estações e dispensários antissezonáticos eram um recurso médico gratuito, o que contribuía para a sua popularização.

Para além disso, os entrevistados reportavam, maioritariamente, as suas memórias a um período em que os serviços antissezonáticos estavam já em pleno funcionamento; ou seja, um período em que as pessoas eram socializadas num meio onde as intervenções dos postos, estações e dispensários antissezonáticos, bem como os recursos oferecidos por esses serviços, tinham sido apropriados e naturalizados na ordem local, assim como nas práticas de reconhecimento e tratamento da malária, de acordo com as experiências pessoais e coletivas que configuravam a doença. 
Como se disse, os sintomas que descreveram na sua caracterização da malária eram sinais suficientes para estabelecerem, por si mesmos, o mal de que padeciam. Por isso, iam ao "posto das sezões" sobretudo pedir os comprimidos e não para um diagnóstico, que já tinham feito. Desta ida ao posto, para além dos comprimidos, aquilo que os entrevistados mais referiram foi a "pica da orelha", procedimento que todos definiam como método de recolha de sangue para análise e confirmação do diagnóstico de "sezões", indispensável para que lhes fossem dados os medicamentos antimaláricos. Mas, como o resultado da "pica da orelha" nem sempre revelava a presença de parasitas no sangue, contrariando o diagnóstico que para si próprios haviam estabelecido, ou, no caso dos trabalhadores migrantes, contrariando o desejo de levar uma reserva de comprimidos no regresso a casa, "levavam sacos cheios de sementes de piorno. Como não levavam medicamento, levavam daquilo para tomar lá" [Campos, Alcácer do Sal, 2005].

Por conseguinte, os medicamentos distribuídos gratuitamente no posto das sezões eram um elemento importante para o interesse dos trabalhadores rurais por aqueles estabelecimentos. Neste ponto, estava implícita uma negociação. Para chegarem a receber gratuitamente os medicamentos, as pessoas tinham de submeter-se à palpação do baço e à recolha da gota de sangue para análise. Esta incursão médica pelo seu corpo era a contrapartida para alcançarem aquilo que realmente pretendiam: os medicamentos que fariam cessar as febres e lhes restituiriam o conforto físico possível, bem como a capacidade de desempenhar as suas funções quotidianas. O reconhecimento do valor terapêutico dos medicamentos que eram receitados nos postos antissezonáticos passava pela experiência física do desaparecimento das febres, de todo o desconforto e incapacidades a estas associados. Assim, suspendiam a toma dos medicamentos quando desapareciam os sintomas, não seguindo a prescrição médica que previa a administração dos antimaláricos segundo o critério da eliminação dos parasitas do sangue.

O pragmatismo subjacente ao reconhecimento e relevância da malária informava também a integração dos postos, estações e dispensários antimalária nos quotidianos, de acordo com as necessidades pessoais. E o mesmo pragmatismo na legitimação destes estabelecimentos levava a que fossem percebidos como mais do que apenas a solução para as infeções maláricas; eram "o desafogo dos pobres", o local onde se procurava remédio para todos os males e não apenas para a malária.

\section{PRÁTICAS PASSADAS E PRESENTES}

Um olhar sobre as práticas passadas relacionadas com a malária, num contexto específico, pode abrir perspetivas de reflexão comparativa sobre a multiplicidade das práticas que presentemente fazem a malária. Por um lado, 
a perspetiva histórica reforça a noção de fluidez das práticas e sua articulação das dimensões macro e microssociais. Por outro, a incidência discursiva nas sensações e ações quotidianas daqueles que reconheciam a malária através do seu próprio corpo - e embora considerando os efeitos que a história tem sobre as memórias pessoais - sugere a centralidade deste, manifesta ou não, enquanto confluência expressiva do sofrimento social, e o modo como esta experiência implica confronto e (des)ajustamento entre práticas distintas que convergem na experiência física da doença.

O exemplo das experiências pessoais de "ter malária", narradas por alguns antigos assalariados rurais portugueses, revela uma malária em que as condições de trabalho, a habitação e a nutrição são convocadas enquanto experiências individuais e comunitárias, congregadas no corpo e sumariadas na constante referência ao sofrimento. A malária define-se por referência a este contexto e não presa à visão médica dos arrozais como locais de criação de mosquitos transmissores, aos abrigos precários como espaços de infeção pela sua vulnerabilidade aos mosquitos, ou à avaliação nutricional e calórica das dietas dos trabalhadores rurais. Enquanto para os médicos se tratava de um problema de saúde pública, uma ameaça à “ordem sanitária”, para esses trabalhadores, a malária dissolvia-se nas muitas contrariedades - reconfiguradas e reavaliadas pela rememoração - que teciam o seu quotidiano, ordenado, fundamentalmente, em torno do trabalho e das relações sociais deste decorrentes. Nesta perspetiva, resultava tanto de sensações físicas imbuídas de significados e de práticas do domínio familiar e comunitário, quanto da incorporação das práticas biomédicas nos quotidianos, das políticas agrárias, das questões de propriedade e exploração da terra e das relações sociais por estas determinadas. Para os trabalhadores rurais, era neste universo que a malária se produzia, trivializando-se e perdendo o protagonismo que lhe era atribuído no discurso médico.

Outras etnografias contemporâneas sobre questões éticas do ensaio da vacina antimalária (Geissler et al. 2008; Gikonyo et al. 2008), ou sobre procura e acesso a cuidados médicos, vulnerabilidade e risco de malária (Ribera e Hausmann-Muela 201 l), mostram que, na malária passada e presente, "doméstica" ou "tropical", estamos perante práticas dinâmicas, localmente produzidas e reformuladas de acordo com circunstâncias variáveis, sujeitas à história assim como à memória individual e coletiva, remota ou recente. As etnografias contam-nos o que as pessoas dizem, fazem, como fazem, como argumentam sobre as ações que materializam a malária no seu quotidiano e para além das quais esta doença não existe para si. Ilustram ainda a importância e mesmo a necessidade de compreender as condições sociopolíticas que determinam essa vulnerabilidade, risco e acesso a cuidados médicos, em sinergia com as condições biológicas (Singer e Clair 2003). Ao mesmo tempo, mostram como estas sinergias condicionam o ordenamento da doença nas necessidades quotidianas. 


\section{BIBLIOGRAFIA}

AMARAL, Luciano, 1994, "Portugal e o passado: política agrária, grupos de pressão e evolução da agricultura portuguesa durante o Estado Novo (1950-1973)", Análise Social, XXIX (128): 889-906.

BAPTISTA, Fernando Oliveira, 1993, A Política Agrária do Estado Novo. Porto, Edições Afrontamento.

BETTENCOURT, Nicolau, 1924, "Alguns aspectos da higiene e da assistência nos Países-Baixos", Jornal da Sociedade das Ciências Médicas de Lisboa, 89 (1-12): 28-55.

BOROWY, Iris, 2007, "International social medicine between the wars: positioning a volatile concept”, Hygiea Internationalis, 6 (2): 13-35.

BOROWY, Iris, 2009, Coming to Terms with World Health: The League of Nations Health Organization 1921-1946. Frankfurt, Peter Lang.

BYNUM, William F., e Vivian NUTTON (orgs.), 1981, Theories of Fever from Antiquity to the Enlightnment. Londres, Wellcome Institute for the History of Medicine (Medical History, supl. 1).

CAMBOURnaC, Francisco J.C., 1938, Sôbre Algumas Medidas de Higiene e Protecção Anti-Sezonática aos "Ranchos Migratórios", separata da revista Clínica, Higiene e Hidrologia. Lisboa, s. ed.

CAmbournaC, Francisco J.C., 1947, Perspectivas Actuais da Luta Anti-Sezonática em Portugal (conferência realizada no Instituto Rocha Cabral em maio de 1947). Lisboa, Imprensa Lucas \& C. ${ }^{\mathrm{a}}$.

CAMBOURNAC, Francisco J.C., 1990, “O Instituto de Malariologia e as suas realizações”, em 50 Anos da Fundação do Instituto de Malariologia e Sua Projecção no Futuro. Águas de Moura, Centro de Estudos de Zoonoses do Instituto Nacional de Saúde Dr. Ricardo Jorge, 1 1-26.

CAMBOURNAC, Francisco J.C., e J.M. Pitta SIMÕES, 1944, "Sobre a alimentação dos 'ranchos migratórios' na região de Águas de Moura”, separata de Lisboa Médica, XXI (4): 205-212.

CARMO, Renato Miguel do, 2007, "As desigualdades sociais nos campos: o Alentejo entre as décadas de 30 e 60 do século XX", Análise Social, XLII (184): 811-835.

CHAVES, José Manuel, 1790, Febriologia - Accomodada tambem para as Pessoas Curiosas. Onde se Descrevem o Caracter, as Causas, e as Especies das Febres Intermittentes, Malignas, e Inflammatorias, conforme a Fiel, e Attenta Observaçaõ, que na Praxe de 20 Annos Tem Feito. Coimbra, Real Officina da Universidade.

CHRISTOPHERS, Colonel Sir S.R., e A. MISSIROLI, 1933, Report on Housing and Malaria: Being a Summary of what is Known about Anophelism in Relation to Housing and Malaria. S. 1., s.ed.

CMP (Câmara Municipal de Palmela), 2001, Memórias do Instituto de Malariologia de Águas de Moura: Da Luta Anti-Palúdica ao Museu. Palmela, Câmara Municipal de Palmela, Centro de Estudos de Vetores e Doenças Infeciosas (Instituto Nacional de Saúde Dr. Ricardo Jorge). COELHO, Eduardo, 1961, Ricardo Jorge: O Médico e o Humanista. Lisboa, Barcelona e Rio de Janeiro, Livraria Luso-Espanhola.

COSTA, Rui Manuel Pinto, 2009, O Poder Médico no Estado Novo, 1945-1974: Afirmação, Legitimação e Ordenamento Profissional. Porto, Universidade do Porto.

Cueto, Marcos, 2007, Cold War, Deadly Fevers: Malaria Eradication in Mexico 1955-1975. Washington, DC, e Baltimore, Woodrow Wilson Center Press e The Johns Hopkins University Press. 
Cutileiro, José, 1977, Ricos e Pobres no Alentejo: Uma Sociedade Rural Portuguesa. Lisboa, Livraria Sá da Costa.

DGS (Direcção-Geral de Saúde), 1944, Sezonismo: A Luta Contra a Endemia no Ano de 1943. S.1., Direcção de Serviços Anti-Sezonáticos, Ministério do Interior - Direcção-Geral de Saúde. FARIA, José Alberto de, 1934, Administração Sanitária. Lisboa, Ministério do Interior/Imprensa Nacional de Lisboa.

FARMER, Paul, 2004, "An anthropology of structural violence", Current Anthropology, 45 (3): 305-317.

FERREIRA, Nuno Estêvão, 2008, "O corporativismo e as instituições do salazarismo: a Câmara Corporativa (1935-1945)”, em António Costa Pinto e Francisco Carlos Palomanes Martinho (orgs.), O Corporativismo em Português: Estado, Política e Sociedade no Salazarismo e no Varguismo. Lisboa, Imprensa de Ciências Sociais, 169-205.

FIGUEIRA, Luís, e Fausto LANDEIRO, 193 1, Malária: Relatório do Curso e Estágio em Hamburgo, Yugoslávia e Itália, separata do Boletim da Agência Geral das Colónias. Lisboa, Agência Geral das Colónias.

FIGUeIRA, Luís, e Fausto LANDeIro, 1932, Relatorio do Primeiro Ano de Luta Anti-Sezonática na Estação de Benavente. Lisboa, Instituto Câmara Pestana.

FREIRE, Francisco, 1952, Um Esboço de Sanidade Rural, separata de Clínica, Higiene e Hidrologia. GEISSLER, P. Wenzel, Ann KELlY, Babatunde IMOUKHUEDE, e Robert POOL, 2008, “'He is now like a brother, I can even give him some blood': relational ethics and material exchanges in a malaria vaccine 'trial community' in the Gambia”, Social Science and Medicine, 67 (5): 696-707.

GIKONYO, Caroline, Philip BEJON, Vicki MARSH, e Sassy MOLYNEUX, 2008, “Taking social relationships seriously: lessons learned from the informed consent practices of a vaccine trial on the Kenyan Coast”, Social Science and Medicine, 67 (5): 708-720.

GORJÃO, Vanda, 2002, Mulheres em Tempos Sombrios: Oposição Feminina ao Estado Novo. Lisboa, Imprensa de Ciências Sociais.

HILl, Rolla B., 1938, Protecção Mecânica da População como Medida Anti-Malárica, separata de Clínica, Higiene e Hidrologia.

HILl, Rolla B., e Francisco J.C. CAMBOURNAC, 1941, Estudo Sobre a Alimentação de Cinco Famílias Rurais numa Herdade do Alentejo, separata de Lisboa Médica.

IGSS (Inspecção-Geral dos Serviços Sanitários), 1903, Epidemiologia: Sobre o Estudo e o Combate do Sezonismo em Portugal. Coimbra, Imprensa da Universidade.

INE, 1960, "População presente e activa total e na agricultura, pecuária e silvicultura por situações na profissão [1950]”, Estatísticas Agrícolas, 27, < http://inenetw02.ine. pt:8080/biblioteca/logon.do> (acesso em 23/12/2012).

INE, 1965, "População residente e activa com profissão ou ocupação, total e na agricultura, pecuária, silvicultura e caça, segundo a situações na profissão ou a ocupação, por distritos [1960]", Estatísticas Agrícolas, 43, <http://inenetw02.ine.pt:8080/biblioteca/logon. do>, (acesso em 23/12/2012).

KLEINMAN, Arthur, Veena DAS, e Margaret LOCK (orgs.), 1996, "Introduction”, Daedalus, 125 (1): XI-XX (número especial sobre o tema "Social suffering").

KLEINMAN, Arthur, Veena DAS, e Margaret LOCK (orgs.), 1997, Social Suffering. Berkeley, Los Angeles e Londres, University of California Press.

LANDEIRO, Fausto, 1942, "O sezonismo e a luta anti-sezonática em Portugal: balanço de dez anos de luta”, em José Alberto de Faria, Sezonismo: Dez Anos de Luta contra a Endemia. 
Lisboa, Direcção dos Serviços Anti-Sezonáticos, Ministério do Interior - Direcção-Geral de Saúde, 11-30.

LANDEIRO, Fausto, e Francisco CAMBOURNAC, s.d., O Sezonismo em Portugal: Relatório do Estudo da Missão Rockefeller Foundation Direç̧ão Geral de Saúde Feito sob a Direç̧ão e Orientação do Dr. Rolla Hill. Lisboa, Agência Geral das Colónias.

LEAGUE OF NATIONS, 1927, Principles and Methods of Antimalarial Measures in Europe: Second General Report of the Malaria Commission. Genebra, League of Nations - Health Organisation. LEAL, João, 2000, Etnografias Portuguesas (1870-1970): Cultura Popular e Identidade Nacional. Lisboa, Dom Quixote.

LEMOS, Alfredo Tovar de, 1932, O Dispensário de Higiene Social de Lisboa: Relatório de 1930 e 1931. Direcção-Geral de Saúde, Dispensário de Higiene Social de Lisboa. Lisboa, Imprensa Nacional.

LÖWY, Ilana, 2001, Virus, moustiques et modernité. Paris, Éditions des Archives Contemporaines. LUCENA, Manuel, 1976, A Evolução do Sistema Corporativo Português, vol. I: O Salazarismo. Lisboa, Perspectivas e Realidades.

LYNCH, Michael, 2001, "Ethnomethodology and the logic of practice", em Theodore R. Schatzki, Karin Knorr-Cetina e Eike von Savigny (orgs.), The Practice Turn in Contemporary Theory. Londres e Nova Iorque, Routledge, 131-148.

MELO, Daniel, 2001, Salazarismo e Cultura Popular (1933-1958). Lisboa, Imprensa de Ciências Sociais.

MIRA, M. Ferreira de, 1948, "Inquérito à alimentação e condições sanitárias do pessoal numa exploração agrícola”, separata de Gazeta Médica Portuguesa, I (2): 37 1-393.

MOL, Annemarie, 2002, The Body Multiple: Ontology in Medical Practice. Durham, NC, e Londres, Duke University Press.

PEREIRA, Luís Silva, e Chiara PUSSETTI (orgs.), 2009, Os Saberes da Cura: Antropologia da Doença e Práticas Terapêuticas. Lisboa, ISPA.

PICKERING, Andrew, 2001, "Practice and posthumanism: social theory and a history of agency", em Theodore R. Schatzki, Karin Knorr-Cetina e Eike von Savigny (orgs.), The Practice Turn in Contemporary Theory. Londres e Nova Iorque, Routledge, 163-174.

PIMENTEL, Irene Flunser, 2000, "A assistência social e familiar do Estado Novo nos anos 30 e 40", Análise Social, XXXIV (151-152): 477-508.

PORTER, Roy, 1999, The Greatest Benefit to Mankind: A Medical History of Humanity. Londres e Nova Iorque, W.W. Norton \& Co.

PUSSETTI, Chiara, 2006, "A patologização da diversidade: uma reflexão antropológica sobre a noção de culture-bound syndrome", Etnográfica, X (1): 5-40.

PUSSETTI, Chiara, e Micol BRAZZABENI (orgs.), 2011 , "Vivenciar o sofrimento social: suas ambiguidades e articulações”, dossiê temático, Etnográfica, 15 (3): 465-586.

RAMOS, Álvaro, 1944, "Sôbre as condições de vida das populações rurais do vale do Sado (inquérito)", em Sezonismo: Trabalhos Originais. S.1., Direcção dos Serviços Anti-Sezonáticos, Ministério do Interior - Direcção-Geral de Saúde, 47-63.

RECKWITZ, Andreas, 2002, "Toward a theory of social practices: a development in culturalist theorizing”, European Journal of Social Theory, 5 (2): 243-263.

REPÚBLICA PORTUGUESA, 1934, "Decreto-Lei n. ${ }^{\circ}$ 24.619”, Ministério do Comércio e Indústria - Direcção-Geral do Comércio e Indústria, Diário do Governo, 254 (29/10/1934): 551.

REPÚBliCA PORTUGUeSA, 1938, "Decreto-Lei n. ${ }^{\circ}$ 28.493", Ministérios do Comércio e Indústria e da Agricultura, Diário do Governo, I série, 41 (19/2/1938): 500-502. 
REPÚBLICA PORTUGUESA, 1945, “Decreto-Lei n. ${ }^{0}$ 35.108”, Ministério do Interior - Subsecretariado de Estado da Assistência Social, Diário do Governo, I série, 247 (7/1 1/1945): 899-922. REPÚBLICA PORTUGUeSA, 1963, "Lei n. ${ }^{\circ} 2120 "$, Presidência da República, Diário do Governo, I série, 169 (19/7/1963): 969-973.

REPÚBLICA PORTUGUESA, 1984, "Decreto-Lei n. ${ }^{\circ}$ 74-C/84, de 2 de Março", Presidência do Conselho de Ministros e Ministérios das Finanças e do Plano e da Saúde, Diário da República, I série, n. ${ }^{\circ} 53$ (2/3/1984), 2. ${ }^{\circ}$ suplemento: 732(5)-732(22).

RIBERA, Joan Muela, e Susanna Hausmann-Muela, 2011, "The straw that breaks the camel's back: redirecting health-seeking behavior studies on malaria and vulnerability", Medical Anthropology Quarterly, 25 (1): 103-121.

ROSAS, Fernando, 1991, "Rafael Duque e a política agrária do Estado Novo (1934-44)", Análise Social, XXVI (112-113): 771-803.

ROSAS, Fernando, 2001, "O salazarismo e o homem novo: ensaio sobre o Estado Novo e a questão do totalitarismo”, Análise Social, XXXV (157): 1031-1054.

ROSAS, Fernando, e J.M. Brandão de BRITO, 1996, "Corporativismo", em Fernando Rosas e J. M. Brandão de Brito (orgs.), Dicionário de História do Estado Novo, vol. 1. Lisboa, Bertrand, 216-224.

ROSAS, Fernando, Fernando MARTINS, Luciano do AMARAL, e Maria Fernanda ROLlO (orgs.), 1994, O Estado Novo (1926-1974), vol. 7 de História de Portugal, dir. José Mattoso. Lisboa, Círculo de Leitores.

ROSEnberG, Charles E., 1992, Explaining Epidemics and Other Studies in the History of Medicine. Cambridge, Cambridge University Press.

SAAVEDRA, Mónica, 2010, "Uma Questão Nacional": Enredos da Malária em Portugal, Séculos XIXe XX. Lisboa, Instituto de Ciências Sociais da Universidade de Lisboa, tese de doutoramento, <http://repositorio.ul.pt/bitstream/10451/1883/1/ulsd058740_td_Monica_Saavedra .pdf $>$.

SANCHES, Ribeiro, 1757, Tratado da Conservaçaõ da Saude dos Povos: Obra Util, e Igualmente Necessaria aos Magistrados, Capitaens Generaes, Capitaens de Mar, e Guerra, Prelados, Abbadessas, Medicos, e Pays de Familias (Com um Appendix Consideraçoens sobre os Terremotos com a Noticia dos Mais Consideraveis de que Faz Mençaõ a Historia, e Deste Ultimo que se Sentio na Europa no 1 de Novembro de 1755). Paris, s.ed.

SCHATZKI, Theodore R., 1996, Social Practices: A Wittgensteinian Approach to Human Activity and the Social. Cambridge, Cambridge University Press.

SCHATZKI, Theodore R., 2001, "Introduction: practice theory”, em Theodore R. Schatzki, Karin Knorr-Cetina e Eike von Savigny (orgs.), The Practice Turn in Contemporary Theory. Londres e Nova Iorque, Routledge, 1-14.

SINGER, Merril, e Scott CLAIR, 2003, "Syndemics and public health: reconceptualizing disease in bio-social context”, Medical Anthropology Quarterly, 17 (4): 423-441.

SNOWDEN, Frank M., 2006, The Conquest of Malaria: Italy, 1900-1962. New Haven e Londres, Yale University Press.

SOCIÉTÉ DES NATIONS, 1931, Conférence Européenne Sur l'Hygiène Rurale (29 juin - 7 juillet 1931): Recommandations sur les principes directeurs de l'organisations de l'assistance médicale, des Services d'Hygiène et d'Assainissement dans les districts ruraux. Genebra, Société des Nations - Organisation d'Hygiène, vol. I.

WILSON, Leonard G., 1993, "Fevers”, em William F. Bynum e Roy Porter (orgs.), Companion Encyclopedia of the History of Medicine, vol. 1. Londres, Routledge, 382-41 1. 